\title{
(C) OPEN ACCESS \\ Inter-relationship between ageing, body mass index, diabetes, systemic blood pressure and intraocular pressure in Asians: 6-year longitudinal study
}

\author{
Jacqueline Chua, ${ }^{1,2}$ Miao Li Chee, ${ }^{1}$ Calvin Woon Loong Chin, 2,3,4 Yih Chung Tham, ${ }^{1}$ \\ Nicholas Tan, ' Sing Hui Lim, ${ }^{1}$ Tin Aung, ${ }^{1,2,4}$ Ching-Yu Cheng, 1,2,4 Tien Yin Wong, 1,2,4 \\ Leopold Schmetterer ${ }^{1,2,5,6,7}$
}

\begin{abstract}
- Additional material is published online only. To view please visit the journal online (http://dx.doi.org/10.1136/ bjophthalmol-2018-311897).
\end{abstract}

${ }^{1}$ Singapore National Eye Centre, Singapore Eye Research Institute, Singapore, Singapore ${ }^{2}$ Academic Clinical Program, Duke-NUS Medical School, Singapore, Singapore

${ }^{3}$ National Heart Centre Singapore, National Heart Research Institute Singapore, Singapore, Singapore

${ }^{4}$ Department of Ophthalmology, Yong Loo Lin School of Medicine, National University of Singapore and National University Health System, Singapore, Singapore

${ }^{5}$ Department of Ophthalmology, Lee Kong Chian School of Medicine, Nanyang Technological University, Singapore, Singapore

${ }^{6}$ Department of Clinical Pharmacology, Medical University of Vienna, Vienna, Austria

${ }^{7}$ Center for Medical Physics and Biomedical Engineering, Medical University of Vienna, Vienna, Austria

\section{Correspondence to}

Professor Leopold Schmetterer, Singapore Eye Research Institute, Singapore National Eye Centre, 11 Third Hospital Avenue, Singapore 168751, Singapore; leopold. schmetterer@seri.com.sg

Received 9 January 2018 Revised 22 February 2018 Accepted 22 March 2018

Published Online First 9 April 2018

\section{Check for updates}

To cite: Chua J, Chee ML,

Chin CWL, et al.

Br J Ophthalmol

2019:103:196-202.

\begin{abstract}
Background To investigate the biological effect of ageing on intraocular pressure (IOP) and risk factors in a population-based cohort study of Malay and Indian adults.
\end{abstract}

Methods Participants aged 40-80 years were recruited for baseline and 6-year follow-up visits between 20042009 and 2010-2015, respectively. Blood pressure (BP) was measured with an automatic BP monitor and IOP were obtained by Goldmann applanation tonometry. Main outcome was change in IOP, defined as the difference between the 6-year IOP and the baseline IOP. Linear regression models were used to investigate the association of changes in IOP with risk factors.

Results Participants without a history of glaucoma or cataract surgery at baseline were included $(n=3188$; mean age: $54 \pm 9$ years) . Their average IOP was reduced $(-0.5 \pm 3.1 \mathrm{~mm} \mathrm{Hg})$, except for those who developed hypertension at follow-up $(0.0 \pm 3.1 \mathrm{~mm} \mathrm{Hg})$. After adjusting for covariates, changes in IOP were negatively associated with age $(\beta=-0.07,95 \% \mathrm{Cl}-0.13$ to -0.01$)$ and positively associated with body mass index, diabetes, hypertension (normotensive as reference group; newly developed hypertensive $(\beta=0.67,95 \% \mathrm{Cl} 0.39$ to 0.95$)$ and chronic hypertensive $(\beta=0.46,95 \% \mathrm{Cl} 0.22$ to $0.70))$, baseline systolic BP (SBP) $(\beta=0.20,95 \% \mathrm{Cl} 0.14$ to 0.26$)$ and diastolic $B P(D B P)(\beta=0.33,95 \% \mathrm{Cl} 0.22$ to $0.44)$, as well as with 6-year increases in SBP $(\beta=0.27$, $95 \% \mathrm{Cl} 0.21$ to 0.33$)$ and $\mathrm{DBP}(\beta=0.52,95 \% \mathrm{Cl} 0.41$ to 0.63).

Conclusions Normal ageing and reduced systemic BP are associated with reduced IOP in Malay and Indian adults. Given that high IOP is a risk factor for glaucoma, our finding highlights the importance of controlling hypertension in older adults, where hypertension and glaucoma incidences are on a rise.

\section{INTRODUCTION}

Clinically, intraocular pressure (IOP) remains the only proven modifiable risk factor for primary open-angle glaucoma (POAG). ${ }^{1}$ Increment in IOP may occur in the absence of identified disease as a part of ageing. There is controversy regarding the biological change in IOP with age. Recent research suggests there may be ethnic/racial differences in IOP patterns. In these prospective studies, IOP decreased in Asian populations, ${ }^{2-8}$ whereas it remained fairly steady over time in Caucasians ${ }^{9}$ and African-origin persons. ${ }^{10} 11$

Direct comparison among these ethnic/racial populations is particularly challenging. First, there have been no longitudinal IOP data on Asian groups other than East Asians (Japanese, ${ }^{348}$ Koreans $^{2} 6$ and Chinese ${ }^{5}$ ). Generally speaking, Japanese are considerably more prone to developing normal tension glaucoma, whereas Chinese persons are more at risk of developing primary angle-closure glaucoma. ${ }^{12}$ Thus, it is unclear if the natural history of IOP among East Asians can reflect that of other Asian groups, who tend to be mostly affected by POAG. ${ }^{13}$ Second, studies on Caucasians ${ }^{9}$ and Africans $^{10} 11$ have used the Goldmann applanation tonometry (GAT), whereas majority of studies on Asians $^{2}{ }^{4-7}$ used non-contact tonometer, except for the Japanese study. ${ }^{3}$ Third, although Nakano and colleagues ${ }^{3}$ have used the gold standard GAT, their study consisted almost exclusively of healthy men who were in their young adulthood, whereas Western and African studies were performed on community-dwelling older adults. Thus, conclusions from the Japanese data must be confined to younger men and should be interpreted with caution for older adults and women. Overall, it remains unclear whether the observed variations among these populations were due to ethnic/racial difference or the discrepancies in study designs and IOP measurement techniques.

It is well known that the aqueous humour production and outflow facility alters with age, ${ }^{14}$ and IOP measurements using the GAT on a representative group of older Asian populations are lacking. At the same time, however, the incidences of various systemic diseases and use of systemic medications ${ }^{15} 16$ increase sharply in those over about 40 years. Given the consistent relationship between systemic blood pressure (BP) levels and hypertension with $\mathrm{IOP}^{17}$ it is clear that the influence of age and systemic BP on IOP is complex and cannot be examined in isolation. In an effort to resolve some of these issues, we investigated the biological effect of ageing on IOP and risk factors for such changes during a 6-year period in a South East Asian population of Singaporean Malays and Indians aged $\geq 40$ years. We hypothesised that there will a biological effect of ageing on IOP, and there will be a synchronous change in IOP in the 
presence of change in systemic BP that often accompany treatment for hypertension.

\section{METHODS}

\section{Study population}

The Singapore Malay Eye study (SiMES) ${ }^{18}$ and Singapore Indian Eye Study (SINDI) ${ }^{19}$ are population-based studies of Malay and Indian adults. Baseline examinations were performed during 2004-2006 for 3280 Malays and 2007-2009 for 3400 Indians. An age-stratified (by 10-year age groups) random sampling was used to select Malays and Indians, aged $\geq 40$ years living across the southwestern part of Singapore. The number of selected subjects was 4168 Malays and 4497 Indians. Of these, 3280 Malays and 3400 Indians participated in the study.

Six-year follow-up examinations were conducted during 2011-2013 for Malays (SiMES-2) ${ }^{20}$ and 2007-2009 for Indians (SINDI-2). ${ }^{21}$ Of the 3280 Malays seen at baseline, 415 had died, 229 were terminally ill, mobility or cognitively impaired or had moved away, and 1901 Malays (response rate 72\%) were re-examined. ${ }^{20}$ Of the 3400 Indians seen at baseline, $201 \mathrm{had}$ died, 285 were terminally ill, mobility or cognitively impaired or had moved away and 2200 Indians (response rate $75 \%$ ) were re-examined. ${ }^{21}$

Both Malay and Indian participants observed at 6-year follow-up examinations were younger $(p<0.001)$, tended to be female $(p=0.001)$, had lower systolic BP (SBP) $(p<0.001)$ than non-participants. However, Malay participants had a lower diastolic BP (DBP) $(79.4 \pm 11.0 \mathrm{~mm} \mathrm{Hg}$ vs $80.4 \pm 11.7 \mathrm{~mm} \mathrm{Hg}$; $\mathrm{p}=0.017$ ) than their non-participants, whereas there was no DBP difference between the Indian participants and Indian nonparticipants $(77.7 \pm 10.1 \mathrm{~mm} \mathrm{Hg}$ vs $77.5 \pm 10.6 \mathrm{~mm} \mathrm{Hg}$; $=0.51)$.

Approval for conducting baseline and follow-up studies, including the consent procedure, was obtained from the Singapore Eye Research Institute Institutional Review Board, and all study procedures adhered to recommendations of the Declaration of Helsinki. Written Informed consent was obtained from all participants.

\section{Examination procedures}

Both Malay and Indian participants underwent similar clinical and ocular examination in the Singapore Eye Research Clinic. SBP and DBP were measured using a digital automatic BP monitor (Dinamap model Pro Series DP110X-RW, Milwaukee, Wisconsin, USA), after subjects were seated for at least $5 \mathrm{~min}$. BP was measured twice, with 5 min apart. A third measurement was taken if previous two SBP readings differed by $>10 \mathrm{~mm} \mathrm{Hg}$ or the DBP by $>5 \mathrm{~mm} \mathrm{Hg}$. The BP of the participant was defined as the mean between the two closest readings.

GAT was used to measure IOP (Haag-Streit, Koeniz, Switzerland) before pupil dilation. ${ }^{22}$ A single drop of topical anaesthesia (amethocaine hydrochloride $0.5 \%$ ) was administered into the inferior conjunctival sac and a dry strip of fluorescein stained the cornea. One reading was taken from each eye and recorded. If the reading was $>21 \mathrm{~mm} \mathrm{Hg}$, then a repeat reading was taken, and the second reading was used.

\section{Other measurements}

A detailed interviewer-administered questionnaire was used to collect demographic data, lifestyle risk factors (eg, smoking), medical history (eg, hypertension and diabetes), ocular history (eg, glaucoma) and medication use. Ethnicities were set by the Singapore census, ${ }^{23}$ and participants were given a choice to be interviewed in English, Malay or Tamil. Blood samples were collected for analysis of haemoglobin A1c (HbA1c) and plasma glucose. Hypertension was defined as SBP $\geq 140 \mathrm{~mm} \mathrm{Hg}$ and/ or DBP $\geq 90 \mathrm{~mm} \mathrm{Hg}$ and/or self-reported physician diagnosed hypertension and/or history of antihypertensive medication. Newly diagnosed hypertensive were defined as individuals having hypertension at follow-up visit but were normotensive at baseline visit. Diabetes was defined as $\mathrm{HbA} 1 \mathrm{c} \geq 6.5 \%$, non-fasting plasma glucose $\geq 11.1 \mathrm{mmol} / \mathrm{L}$, self-reported physician diagnosed diabetes or history of glucose-lowering medication. Participants' height was measured in centimetres using a wall-mounted measuring tape, and weight was measured in kilograms using a digital scale (SECA, model 782 2321009,

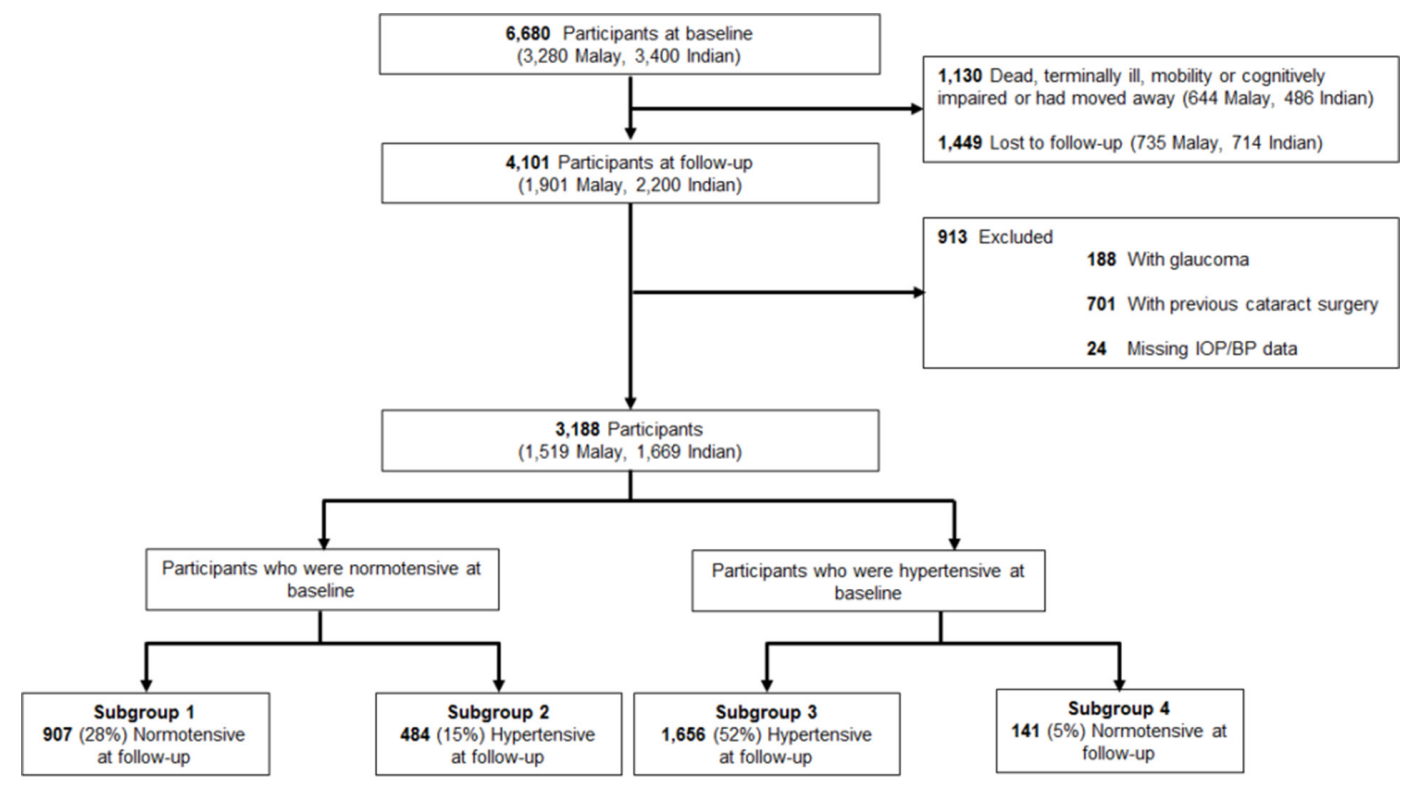

Figure 1 Identification of eligible participants from the Singapore Malay Eye study and Singapore Indian Eye study observed at both baseline and 6-year examinations. Of the 4101 participants who participated at the baseline and follow-up examinations, 3188 were included in the analysis, of which 484 (15\%) developed hypertension at 6-year follow-up. BP, blood pressure; IOP, intraocular pressure. 


\begin{tabular}{|c|c|c|c|c|c|c|}
\hline Subgroups & & Subgroup 1 & Subgroup 2 & Subgroup 3 & Subgroup 4 & \\
\hline Baseline & & Normotensive & Normotensive & Hypertensive & Hypertensive & \\
\hline Follow-up & Total & Normotensive & Hypertensive & Hypertensive & Normotensive & $P$ values* \\
\hline Number of participants, \% & $3188(100)$ & $907(28)$ & $484(15)$ & $1656(52)$ & $141(5)$ & \\
\hline Number of eyes & 6376 & 1814 & 968 & 3312 & 282 & \\
\hline Age, years & $54.4 \pm 8.5$ & $50.1 \pm 6.5$ & $52.5 \pm 7.3$ & $57.5 \pm 8.6$ & $52.7 \pm 8.2$ & $<0.001$ \\
\hline Gender, female & $1678(53)$ & $470(52)$ & $261(54)$ & $883(53)$ & $64(45)$ & 0.278 \\
\hline \multicolumn{7}{|l|}{ Ethnicity } \\
\hline Malays & $1519(48)$ & $365(40)$ & $207(43)$ & $871(53)$ & $76(54)$ & \multirow[t]{2}{*}{$<0.001$} \\
\hline Indians & $1669(52)$ & $542(60)$ & $277(57)$ & $785(47)$ & $65(46)$ & \\
\hline \multicolumn{7}{|l|}{ Smoking Status } \\
\hline Never & $2235(70)$ & $628(69)$ & $331(69)$ & $1188(72)$ & $88(63)$ & \multirow[t]{3}{*}{$<0.001$} \\
\hline Current smoker & $534(17)$ & $189(21)$ & $93(19)$ & $215(13)$ & $34(26)$ & \\
\hline Past smoker & $415(13)$ & $88(10)$ & $60(12)$ & $251(15)$ & $16(11)$ & \\
\hline Body mass index, $\mathrm{kg} / \mathrm{m}^{2}$ & $26.4 \pm 4.6$ & $25.0 \pm 4.1$ & $26.2 \pm 4.4$ & $27.3 \pm 4.7$ & $26.0 \pm 4.7$ & $<0.001$ \\
\hline Diabetes & $915(30)$ & $125(16)$ & $122(26)$ & $639(40)$ & $29(21)$ & $<0.001$ \\
\hline HbA1c (\%) & $6.3 \pm 1.4$ & $5.8 \pm 0.8$ & $6.3 \pm 1.6$ & $6.5 \pm 1.4$ & $6.2 \pm 1.2$ & $<0.001$ \\
\hline \multicolumn{7}{|l|}{ Blood pressure, $\mathrm{mm} \mathrm{Hg}$} \\
\hline Systolic & $137.2 \pm 21.2$ & $119.2 \pm 10.6$ & $127.5 \pm 8.6$ & $149.8 \pm 20.14$ & $139.0 \pm 13.7$ & $<0.001$ \\
\hline Diastolic & $78.9 \pm 10.6$ & $72.7 \pm 7.0$ & $75.9 \pm 7.1$ & $83.0 \pm 11.3$ & $80.9 \pm 9.0$ & $<0.001$ \\
\hline \multicolumn{7}{|c|}{ Change in blood pressure, $\mathrm{mm} \mathrm{Hg}$} \\
\hline Systolic & $0.2 \pm 19.6 \dagger$ & $2.9 \pm 11.2 \dagger$ & $14.0 \pm 16.2 \dagger$ & $-4.4 \pm 22.0 \dagger$ & $-10.3 \pm 13.8 \dagger$ & $<0.001$ \\
\hline Diastolic & $-1.2 \pm 10.5 \dagger$ & $1.0 \pm 6.8 \dagger$ & $5.0 \pm 8.9 \dagger$ & $-4.0 \pm 11.5 \dagger$ & $-4.4 \pm 8.9 \dagger$ & $<0.001$ \\
\hline \multicolumn{7}{|l|}{ Antihypertensive medications } \\
\hline Neither examinations & $1782(56)$ & $887(100)$ & $341(71)$ & $437(26)$ & $117(85)$ & \multirow[t]{4}{*}{$<0.001$} \\
\hline Baseline only & $141(5)$ & - & - & $121(7)$ & $20(15)$ & \\
\hline Follow-up only & $500(16)$ & - & $139(29)$ & $361(22)$ & - & \\
\hline Both examinations & $737(23)$ & - & - & $737(45)$ & - & \\
\hline IOP, mm Hg & $15.4 \pm 3.0$ & $14.9 \pm 2.9$ & $15.4 \pm 2.9$ & $15.7 \pm 3.0$ & $15.5 \pm 2.9$ & $<0.001$ \\
\hline Change in IOP, mm Hg & $-0.5 \pm 3.1 \dagger$ & $-0.4 \pm 3.0 \dagger$ & $0.0 \pm 3.1$ & $-0.6 \pm 3.2 \dagger$ & $-0.8 \pm 3.1 \dagger$ & $<0.001$ \\
\hline
\end{tabular}

Data are mean \pm SD or number $(\%)$, as appropriate.

${ }^{*}$ Test for differences between hypertensive groups, based on one-way analysis of variance test for continuous variables and with $\chi^{2}$ tests for categorical variables.

$+P<0.05$. Test for differences in continuous variables between baseline versus follow-up, based on Wilcoxon matched-pairs signed-ranks test.

IOP, intraocular pressure.

Germany). Smoking status was defined as those never smoked, current smokers and past smokers. Body mass index (BMI) was calculated as body weight (in kilograms) divided by body height (in metres) squared.

\section{Statistical analyses}

All baseline values were defined as obtained during baseline examinations. Primary outcome was change in IOP, defined as the difference between the 6-year IOP and the baseline IOP (ie, IOP at 6-year visit minus IOP at baseline). To compare the characteristics of participants among groups, one-way analysis of variance test was performed for continuous variables, and $\chi^{2}$ test was used for categorical variables. There was a strong correlation between the intereye IOPs in the baseline $(r=0.893$, $\mathrm{p}<0.001)$ and follow-up $(\mathrm{r}=0.891, \mathrm{p}<0.001)$ IOPs. GEE is able to appropriately account for intereye correlation as well as to maximise power and precision of the dataset. ${ }^{24} 25$ Association between ocular and systemic factors (independent variables) with changes in IOP (dependent variable) were assessed using multivariate linear regression models with generalised estimating equations that accounted for intereye correlation. In addition to age, gender, ethnicity and baseline IOP, factors with $p<0.10$ in the first model were included in the multivariate model. Hypertension status was coded as a set of indicator variables with normotension as the reference group. Data were analysed with statistical software (STATA, V.13.1).

\section{RESULTS}

Of the 4101 participants who participated at the baseline and 6-year follow-up examinations, we excluded 188 participants (376 eyes) with a history of glaucoma diagnosis or glaucoma surgery or medication because their IOP may be biassed. ${ }^{26}$ We further excluded 701 participants (1402 eyes) who had undergone cataract surgery because pseudophakic eyes tended to have lower IOP. ${ }^{22} 27$ We also excluded 24 participants on the basis of missing IOP and BP clinical variables (figure 1). Of the remaining 3188 persons, 484 (15\%) developed hypertension at 6-year follow-up.

Table 1 shows the baseline clinical characteristics of participants stratified by hypertensive status. Mean age and SD of participants was $54.4 \pm 8.5$ years, $53 \%$ were female and $48 \%$ were Malays. Over the 6-year period, systemic BP increased in those who remained normotensive as well as those who developed hypertension, whereas it decreased in those who remained hypertensive $(\mathrm{p}<0.001)$. At baseline, the mean IOP was $15.4 \pm 3.0 \mathrm{~mm} \mathrm{Hg}$ and was lowest for those who were normotensive compared with those with hypertension $(14.9 \mathrm{~mm} \mathrm{Hg}$ vs $15.4-15.7 \mathrm{~mm} \mathrm{Hg} ; \mathrm{p}<0.001)$. Mean IOP decreased by -0.4 
Table 2 Association with changes in intraocular pressure (IOP) assessed using multivariate linear regression models with generalised estimating equations ( $n=3188$ persons; 6376 eyes)

\begin{tabular}{|c|c|c|}
\hline \multirow[b]{3}{*}{ Characteristics } & \multicolumn{2}{|l|}{ Change in IOP $(\mathrm{mm} \mathrm{Hg})$} \\
\hline & \multicolumn{2}{|l|}{$\boldsymbol{\beta}(95 \% \mathrm{Cl})$} \\
\hline & Model 1† & Model $2 \ddagger^{*}$ \\
\hline Age, per 5 years & $-0.02(-0.07$ to 0.03$)$ & $\begin{array}{l}-0.07(-0.13 \text { to } \\
-0.01)^{*}\end{array}$ \\
\hline Gender, female & $0.46(0.29 \text { to } 0.64)^{* *}$ & $0.35(0.12 \text { to } 0.58)^{*}$ \\
\hline \multicolumn{3}{|l|}{ Ethnicity } \\
\hline Malays & Reference & Reference \\
\hline Indians & $0.69(0.51 \text { to } 0.86)^{* *}$ & $0.70(0.52 \text { to } 0.89)^{\star *}$ \\
\hline Baseline IOP, mm Hg & $\begin{array}{l}-0.68(-0.70 \text { to } \\
-0.65)^{* *}\end{array}$ & $\begin{array}{l}-0.69(-0.71 \text { to } \\
-0.66)^{* *}\end{array}$ \\
\hline \multicolumn{3}{|l|}{ Smoking status } \\
\hline Never & Reference & \\
\hline Current smoker & $-0.22(-0.51$ to 0.07$)$ & - \\
\hline Past smoker & $-0.14(-0.46$ to 0.19$)$ & - \\
\hline Body mass index, $\mathrm{kg} / \mathrm{m}^{2}$ & $0.04(0.02 \text { to } 0.06)^{* *}$ & $0.02(0.01 \text { to } 0.04)^{*}$ \\
\hline Diabetes & $0.40(0.19 \text { to } 0.60)^{* *}$ & $0.27(0.06 \text { to } 0.49)^{*}$ \\
\hline $\mathrm{HbA1c}(\%)$ & $0.09(0.03 \text { to } 0.16)^{*}$ & $0.05(-0.02$ to 0.12$)$ \\
\hline \multicolumn{3}{|l|}{ Hypertensive status } \\
\hline $\begin{array}{l}\text { Subgroup 1: normotensive at } \\
\text { baseline and follow-up }\end{array}$ & Reference & Reference \\
\hline $\begin{array}{l}\text { Subgroup 2: normotensive at } \\
\text { baseline and hypertensive at } \\
\text { follow-up }\end{array}$ & $0.76(0.49 \text { to } 1.04)^{* *}$ & $0.67(0.39 \text { to } 0.95)^{* *}$ \\
\hline $\begin{array}{l}\text { Subgroup 3: hypertensive at } \\
\text { baseline and follow-up }\end{array}$ & $0.60(0.38 \text { to } 0.82)^{* *}$ & $0.46(0.22 \text { to } 0.70)^{* *}$ \\
\hline $\begin{array}{l}\text { Subgroup 4: hypertensive at } \\
\text { baseline and normotensive at } \\
\text { follow-up }\end{array}$ & $0.22(-0.20$ to 0.63$)$ & $0.18(-0.24$ to 0.60$)$ \\
\hline \multicolumn{3}{|c|}{$\begin{array}{l}\text { *Denotes } \mathrm{P}<0.05 \text {. } \\
\text { **Denotes } \mathrm{P}<0.001 \text {. } \\
\text { †Model } 1 \text { adjusted for age, gender, ethnicity and IOP. } \\
\text { †Model } 2 \text { adjusted for age, gender, ethnicity, IOP, body mass index, diabetes and } \\
\text { hypertensive. When HbA1c was assessed as an exposure, diabetes was removed } \\
\text { from the model. } \\
\text {-, data were intentionally omitted; HbA1c, haemoglobin A1c. }\end{array}$} \\
\hline
\end{tabular}

to $-0.8 \mathrm{~mm} \mathrm{Hg}$ for most groups; in contrast, IOP changes were symmetric around zero for individuals who were newly diagnosed with hypertension (subgroup 2: $0.0 \pm 3.1 \mathrm{~mm} \mathrm{Hg}$; $\mathrm{p}=0.299)$.

Factors associated with 6-year IOP change were explored by linear regression modelling (table 2). The age-adjusted, gender-adjusted, ethnicity-adjusted and baseline IOP-adjusted analyses found female gender, ethnicity, baseline IOP, BMI, diabetes, HbA1c and hypertension to be associated with IOP change (model 1, table 2). Multivariable analysis showed that changes in IOP were negatively associated with age $(\beta=-0.07$, $95 \% \mathrm{CI}-0.13$ to -0.01$)$ and baseline IOP $(\beta=-0.69,95 \% \mathrm{CI}$ -0.71 to -0.66$)$, and positively associated with female gender ( $\beta=0.35,95 \%$ CI 0.12 to 0.58$)$, Indian ethnicity $(\beta=0.70,95 \%$ CI 0.52 to 0.89$)$, BMI $(\beta=0.02,95 \%$ CI 0.01 to 0.04$)$, diabetes $(\beta=0.27,95 \%$ CI 0.06 to 0.49 ), hypertension (normotensive as reference group; newly developed hypertensive $(\beta=0.67,95 \%$ CI 0.39 to 0.95$)$ and chronic hypertensive $(\beta=0.46,95 \%$ CI 0.22 to 0.70 ; model 2 , table 2$)$ ). No interactions between age and gender or ethnicity were noted ( $\mathrm{p}$ for interaction $=0.854$ for gender; 0.144 for ethnicity).
In separate models that considered baseline SBP or DBP rather than hypertension, 6-year changes in IOP were related to higher baseline SBP $(\beta=0.20,95 \%$ CI 0.14 to 0.26$)$ and DBP $(\beta=0.33$, $95 \%$ CI 0.22 to 0.44 ), as well as with 6-year increases in SBP $(\beta=0.27,95 \%$ CI 0.21 to 0.33$)$ or DBP $(\beta=0.52,95 \%$ CI 0.41 to 0.63 ; table 3$)$. That is, for every $10 \mathrm{~mm} \mathrm{Hg}$ increase in SBP or DBP, there was a $0.27 \mathrm{~mm} \mathrm{Hg}$ or $0.52 \mathrm{~mm} \mathrm{Hg}$ increase in IOP, respectively. Further analysis stratified by hypertensive status showed that such trends of increasing IOP as levels of SBP or DBP increased were mostly consistent across all groups (table 3). Only baseline use of antihypertensive medications was associated with increase in IOP, whereas use of medications at follow-up only was not associated with change in IOP.

We next considered the effect of various antihypertensive medication classes on hypertensive participants who received antihypertensive medications only during follow-up (online supplementary file 1). These were 139 participants from subgroup 2 and 361 from subgroup 3. After adjusting for age, gender, ethnicity, IOP, BMI, diabetes, SBP and change in SBP, lower IOP was found in participants taking $\beta$-blockers $(\beta=-0.55,95 \% \mathrm{CI}-0.96$ to $-0.13 ; p=0.01)$. The association with $\beta$-blockers remained significant when adjustments were made for DBP ( $\beta=-0.50,95 \%$ CI -0.93 to -0.07$)$. However, change in IOP was not significantly associated with participants on other medication classes (online supplementary table 1; $\mathrm{p}>0.05$ ).In a separate model that considered $\beta$-blockers rather than use of antihypertensive medications (online supplementary table 2), 6-year changes in IOP were related with 6-year increases in SBP $(\beta=0.27,95 \%$ CI 0.17 to 0.31$)$ or DBP $(\beta=0.33,95 \%$ CI 0.06 to 0.60 ).

Figure 2 further illustrates the trend observed between age group and BP increments with changes in IOP as seen in the multivariable linear regression model. Individuals who were older ( $\mathrm{p}$ trend $=0.012$; figure $2 \mathrm{~A}$ ) had a larger decrease in IOP. It was $-0.36 \pm 0.16 \mathrm{~mm} \mathrm{Hg}$ for persons $40-49$ years, $-0.51 \pm 0.14$ $\mathrm{mm} \mathrm{Hg}$ for those $50-59$ years, $-0.55 \pm 0.22 \mathrm{~mm} \mathrm{Hg}$ for those $60-69$ years and $-0.94 \pm 0.40 \mathrm{~mm} \mathrm{Hg}$ for those 70 years or older. In terms of BP increments, there was a mean decrease of $-0.39 \pm 0.14 \mathrm{~mm} \mathrm{Hg}$ in IOP over the 6-year interval for those whose SBP was within $10 \mathrm{~mm} \mathrm{Hg}$ of their baseline BP compared with a decrease of $-0.04 \pm 0.18 \mathrm{~mm} \mathrm{Hg}$ for those whose SBP increased by $10 \mathrm{~mm} \mathrm{Hg}$ and a decrease of $-1.18 \pm 0.20 \mathrm{~mm} \mathrm{Hg}$ in IOP for those whose SBP decreased by $10 \mathrm{~mm} \mathrm{Hg}$ or more ( $\mathrm{p}$ trend $<0.001$; figure $2 \mathrm{~B}$ ). Values for change in IOP for similar changes in DBP were $-0.38 \pm 0.12,0.08 \pm 0.26$ and $-1.35 \pm 0.26$ $\mathrm{mm} \mathrm{Hg}$, respectively.

We evaluated the effects of timing variations (eg, morning of the baseline visit and evening follow-up or vice versa) or seasonal variations (eg, warmer months at baseline vs cooler months at follow-up) on IOP measurements. No significant effects were found (data not shown).

\section{DISCUSSION}

After 6 years of follow-up, normal ageing is associated with a reduced IOP, while individuals who were women, of Indian ethnicity, with diabetes, those having higher BMI and greater change in systolic and diastolic BP are associated with greater change in IOP in these Malay and Indian populations living in Singapore. Understanding changes in IOP over time and their related factors may be relevant when managing patients with glaucoma who are also receiving treatment for systemic comorbidities. To our knowledge, our study is the first epidemiological study on South East Asians that assessed the biological effects of 
Table 3 Association with changes in intraocular pressure (IOP) by hypertensive status assessed using multivariate linear regression models with generalised estimating equations

\begin{tabular}{|c|c|c|c|c|}
\hline \multirow[b]{3}{*}{ Characteristics } & \multicolumn{4}{|l|}{ Change in IOP $(\mathrm{mm} \mathrm{Hg})$} \\
\hline & \multicolumn{4}{|l|}{$\boldsymbol{\beta}(95 \% \mathrm{Cl})$} \\
\hline & $\begin{array}{l}\text { All }(n=3188 \text { persons; } \\
6376 \text { eyes) } t\end{array}$ & $\begin{array}{l}\text { Subgroup } 1 \text { ( } n=907 \\
\text { persons; } 1814 \text { eyes) } \ddagger\end{array}$ & $\begin{array}{l}\text { Subgroups } 2 \text { and } 3(n=2140 \\
\text { persons; } 4280 \text { eyes) } \dagger\end{array}$ & $\begin{array}{l}\text { Subgroup } 4(n=141 \\
\text { persons; } 282 \text { eyes) } \ddagger\end{array}$ \\
\hline \multicolumn{5}{|l|}{ Model with SBP } \\
\hline Baseline SBP, per $10 \mathrm{~mm} \mathrm{Hg}$ & $0.20(0.14 \text { to } 0.26)^{* *}$ & $0.31(0.12 \text { to } 0.50)^{*}$ & $0.16(0.09 \text { to } 0.24)^{* *}$ & $-0.04(-0.55$ to 0.45$)$ \\
\hline Change in SBP, per $10 \mathrm{~mm} \mathrm{Hg}$ & $0.27(0.21 \text { to } 0.33)^{* *}$ & $0.31(0.20 \text { to } 0.57)^{* *}$ & $0.24(0.17 \text { to } 0.31)^{* *}$ & $0.26(-0.18$ to 0.71$)$ \\
\hline \multicolumn{5}{|l|}{ Antihypertensive medications } \\
\hline Neither examinations & Reference & - & Reference & Reference \\
\hline Baseline only & $0.43(-0.01$ to 0.97$)$ & - & $0.62(0.02 \text { to } 1.23)^{*}$ & $-1.34(-2.81$ to 0.13$)$ \\
\hline Follow-up only & $-0.01(-0.23$ to 0.27$)$ & - & $-0.04(-0.36$ to 0.28$)$ & - \\
\hline Both examinations & $0.02(-0.23$ to 0.27$)$ & - & $0.01(-0.29$ to 0.30$)$ & - \\
\hline \multicolumn{5}{|l|}{ Model with DBP } \\
\hline Baseline DBP, per $10 \mathrm{~mm} \mathrm{Hg}$ & $0.33(0.22 \text { to } 0.44)^{* *}$ & $0.29(0.01 \text { to } 0.59)^{*}$ & $0.27(0.14 \text { to } 0.41)^{* *}$ & $0.14(-0.53$ to 0.81$)$ \\
\hline Change in DBP, per $10 \mathrm{~mm} \mathrm{Hg}$ & $0.52(0.41 \text { to } 0.63)^{* *}$ & $0.57(0.27 \text { to } 0.87)^{* *}$ & $0.45(0.32 \text { to } 0.58)^{* *}$ & $0.67(0.06 \text { to } 1.28)^{*}$ \\
\hline \multicolumn{5}{|l|}{ Antihypertensive medications } \\
\hline Neither examinations & Reference & - & Reference & Reference \\
\hline Baseline only & $0.47(-0.06$ to 1.01$)$ & - & $0.60(0.01 \text { to } 1.21)^{*}$ & $\begin{array}{l}-1.12(-2.22 \text { to } \\
-0.02)^{*}\end{array}$ \\
\hline Follow-up only & $0.05(-0.22$ to 0.33$)$ & - & $-0.07(-0.39$ to 0.25$)$ & - \\
\hline Both examinations & $0.06(-0.18$ to 0.31$)$ & - & $-0.03(-0.32$ to 0.26$)$ & - \\
\hline
\end{tabular}

Subgroups refer to hypertensive status: subgroup 1: normotensive at baseline and follow-up; subgroup 2: normotensive at baseline and hypertensive at follow-up; subgroup 3:

hypertensive at baseline and follow-up; and subgroup 4: hypertensive at baseline and normotensive at follow-up.

${ }^{*}$ Denotes $P<0.05$.

${ }^{* *}$ Denotes $\mathrm{P}<0.001$

†Model with SBP (or DBP) adjusted for age, gender, ethnicity, IOP, body mass index, diabetes, SBP (or DBP), change in SBP (or change in DBP) and antihypertensive medications.

¥Model with SBP (or DBP) adjusted for age, gender, ethnicity, IOP, body mass index, diabetes, SBP (or DBP) and change in SBP (or change in DBP).

-, data were intentionally omitted; DBP, diastolic blood pressure; IOP, intraocular pressure; SBP, systolic blood pressure.

IOP and the factors affecting its trend by using the same methodology to collect data over the 6 years.

There is little doubt that IOP decreased with ageing in Asians (table 2 and figure 2A). Data from our study and previous work on East Asian populations ${ }^{236-8}$ support this relationship. In vast majority of individuals, there was a minimal decrease of $0.4-0.6$ $\mathrm{mm} \mathrm{Hg}$ in IOP over the 6 years; in contrast, IOP changes were symmetric around zero for individuals who were newly diagnosed with systemic hypertension, who correspondingly had the greatest increase in BP. We can better appreciate the neutralising effect of systemic hypertension on the biological ocular hypotensive effect of ageing when we stratified our participants based on the recency of hypertensive status. However, none of the Caucasian and African studies have stratified the participants based on the recency of systemic hypertension onset, typically signified by a substantial increase in BP; it is conceivable that the hypotensive effect of ageing may have been overshadowed or nullified by the ocular hypertensive effect of systemic hypertension and IOP therefore increases with age or remains unchanged, respectively.

Information on the natural history of IOP in Asian population is of scientific interest as it may uncover important insights into the pathogenesis and risk for POAG. One long-standing hypothesis that has emerged to explain the greater burden of POAG in the elderly stresses the importance of age-related elevation of IOP, where the elevated IOP directly compresses the optic nerve head, thereby distorting the lamina cribrosa and interrupting the axoplasmic flow, ultimately resulting in the death of the retinal ganglion cells. ${ }^{28}$ The decrease in IOP with advancing age, although modest, clearly does not support the notion that the age-related nature of POAG is mediated via an increase in IOP with age. Rather, the increase of prevalence of POAG with age may be explained by a greater susceptibility of the optic nerve head to IOP or other non-IOP-related risk factors. ${ }^{29}$ Unfortunately, our understanding of the mechanism on the biologically decreasing trend of IOP is far from complete. The most likely explanation may be the age-related decline in aqueous humour production, ${ }^{30}$ partially counteracted by the increase in aqueous outflow resistance. ${ }^{14}$ This decrease of aqueous humour production may be more pronounced in Asians than other populations, although this hypothesis needs confirmation in future studies.

Glaucoma-related changes to IOP levels can be confounded by normal ageing as well as systemic comorbidities. We found that individuals who have diabetes, were hypertensives, with higher BMI and higher SBP and DBP levels exhibited higher IOP levels, adding another layer of complexity to determining the 'true' IOP of the eye. Similarly, other longitudinal studies have shown that the IOP is influenced by systemic parameters such as diabetes, ${ }^{910} \mathrm{BMI}^{3}$ and BP levels. ${ }^{3910}$ Elevated IOP is a common cause of referral to eye care services, and current care model requires the regular monitoring of high-risk suspects. ${ }^{31}$ Our findings indicate that individuals without evidence of glaucoma may potentially be at risk of higher IOP, depending on their control of BP. In view of the rising burden of systemic hypertension in people worldwide, ${ }^{32}$ together with the compulsory referral of high-risk suspects, uncontrolled systemic hypertension can lead to an increasing and unnecessary referrals for ophthalmological investigations, significantly an impact to the quality and costs of healthcare services.

The mechanism underlying the relation between BP and IOP is unclear based on the present data. However, it may be related to the increase of ocular perfusion pressure that is often associated with an increased aqueous production. Linear relationship 
A

Change in IOP stratified by age group
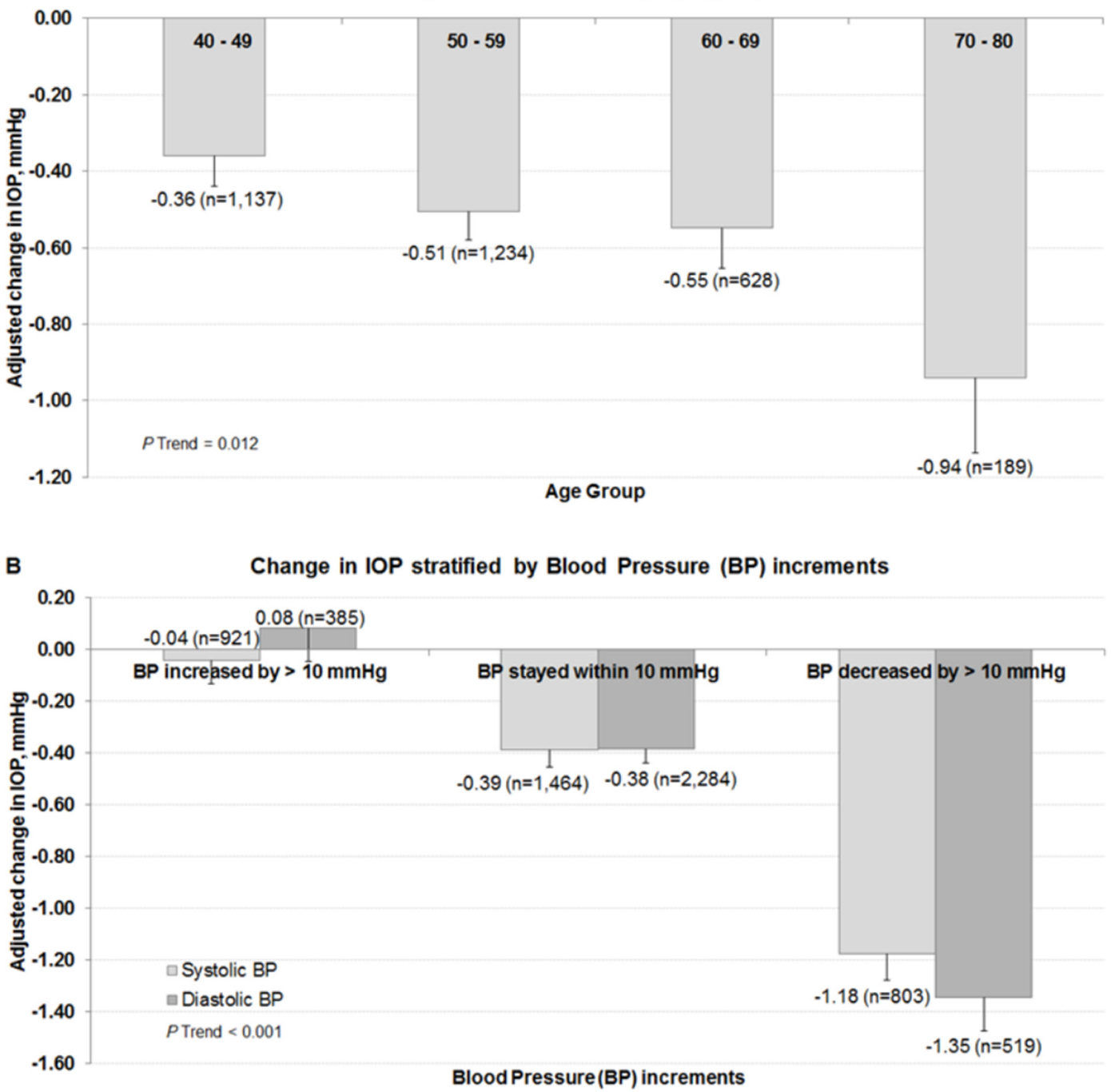

Figure 2 Distribution of change in IOP stratified by (A) age groups and (B) blood pressure increments. *Data and $p$ values shown for age groups are after adjustment for age group, gender, ethnicity, IOP, smoking, body mass index, diabetes and hypertensive status. $+D a t a$ and $p$ values shown for change in blood pressure increments are after adjustment for age, gender, ethnicity, IOP, smoking, body mass index, diabetes, SBP (or DBP), change in SBP (or change in DBP) and antihypertensive medications. DBP, diastolic blood pressure; IOP, intraocular pressure; SBP, systolic blood pressure.

between aqueous humour production and ciliary blood flow have been reported until above a threshold level of perfusion. ${ }^{33}$ Alternatively, the dependence of IOP on BP may be related to the increase in choroidal volume with the elevation of BP. Studies have observed an ocular pressure-volume relationship that is dependent on the level of the mean arterial pressure. ${ }^{34} 35$ Another plausible explantion is that the atherosclerotic processes have led to the increase in BP, thereby causing an increase in the aqueous outflow resistance. Higher levels of IOP has been shown to be significantly associated with the presence of coronary artery calcium, independent of conventional cardiovascular risk factors. ${ }^{36}$ In the present study, however, treatment of systemic hypertension was associated with normalisation of the IOP-BP relation, indicating that the association is rather dependent on the actual BP level than on the presence of hypertension. Finally, we cannot exclude the possibility of BP-lowering drugs having a direct pharmacological effect on either outflow resistance or aqueous humour production. $\mathrm{We}^{15}$ and others ${ }^{16}$ have found that participants using systemic $\beta$-blocker, a commonly prescribed BP-lowering drug, had lowered IOP. Unfortunately, the sample size in the current study was inadequate for a subgroup analysis, based on various systemic antihypertensive agents.

\section{Study strengths and limitations}

Strengths of the study included population-based study, high participation rate (follow-up of $72 \%$ of survivors) and availability of two major Asian ethnic groups with similar standardised study methodology. The use of gold standard GAT equipment further strengthened the study. However, our study had a few limitations. Patients lost to follow-up were older, had higher systemic BP and had higher prevalence of hypertension. These could have underestimated the relation between change in BP and change in IOP. Second, misclassification of hypertension status as derived from the clinical examinations may have occurred because the classification was based, in part, on two measurements of the BP during a single examination. When we analysed the data for hypertension status based on the follow-up examination findings, we found that approximately $4 \%$ of the participants who were initially classified as hypertensive were now deemed normotensive during the follow-up. Lastly, only 
one IOP measurement was taken in each eye at each visit, which is less accurate than having multiple IOP measurements.

In conclusion, after 6-year follow-up, our population-based study of Malay and Indian adults living in Singapore revealed that IOP shows a biological decrease with age. We have also found that changes in IOP are directly and significantly associated with changes in systemic BP, particularly in subjects with established systemic hypertension. Our finding highlights the importance of BP control in patients with glaucoma as this will result in the lowering of IOP over time. Given that high IOP is a major glaucoma risk factor, it underscores the importance of controlling BP in older adults, where glaucoma burden is especially high.

Correction notice This article has been corrected since it was published Online First. The corresponding address has been changed to Professor Schmetterer's Singapore address.

Contributors JC and LS had full access to all the data in the study and take responsibility for the integrity of the data and the accuracy of the data analysis. Study concept and design: C-YC, TYW and LS. Acquisition, analysis or interpretation of data: all authors. Drafting of the manuscript: JC and LS. Critical revision of the manuscript for important intellectual content: all authors. Statistical analysis: MLC and JC. Obtained funding: TYW, C-YC and LS. Administrative, technical or material support: all authors. Study supervision: JC, YCT, NT and SHL.

Funding The study is funded by National Medical Research Council (grants 0796/2003, IRG07nov013, IRG09nov014, STaR/0003/2008; CG/SERI/2010; NMRC/ CG/C010A/2017) and Biomedical Research Council (grants 08/1/35/19/550 and 09/1/35/19/616), Singapore. C-YC is supported by National Medical Research Council (NMRC/CSA/033/2012)

Disclaimer The sponsor or funding organisation had no role in the design or conduct of this research.

Competing interests None declared.

Patient consent Not required.

Ethics approval Singapore Eye Research Institute Institutional Review Board.

Provenance and peer review Not commissioned; externally peer reviewed.

Data sharing statement Additional unpublished data may be available from the corresponding author.

Open access This is an open access article distributed in accordance with the Creative Commons Attribution Non Commercial (CC BY-NC 4.0) license, which permits others to distribute, remix, adapt, build upon this work non-commercially, and license their derivative works on different terms, provided the original work is properly cited, appropriate credit is given, any changes made indicated, and the use is non-commercial. See: http://creativecommons.org/licenses/by-nc/4.0

Co Author(s) (or their employer(s)) 2019. Re-use permitted under CC BY-NC. No commercial re-use. See rights and permissions. Published by BMJ.

\section{REFERENCES}

1 Garway-Heath DF, Crabb DP, Bunce C, et al. Latanoprost for open-angle glaucoma (UKGTS): a randomised, multicentre, placebo-controlled trial. Lancet 2015;385:1295-304.

2 Baek SU, Kee C, Suh W. Longitudinal analysis of age-related changes in intraocular pressure in South Korea. Eye 2015;29:625-9.

3 Nakano T, Tatemichi M, Miura Y, et al. Long-term physiologic changes of intraocular pressure: a 10-year longitudinal analysis in young and middle-aged Japanese men. Ophthalmology 2005;112:609-16.

4 Nomura $\mathrm{H}$, Shimokata $\mathrm{H}$, Ando F, et al. Age-related changes in intraocular pressure in a large Japanese population: a cross-sectional and longitudinal study. Ophthalmology 1999;106:2016-22.

5 Han X, Niu Y, Guo X, et al. Age-related changes of intraocular pressure in elderly people in Southern China: Lingtou Eye Cohort Study. PLoS One 2016;11:e0151766.

6 Zhao D, Kim MH, Pastor-Barriuso R, et al. A longitudinal study of age-related changes in intraocular pressure: the Kangbuk Samsung Health Study. Invest Ophthalmol Vis Sci 2014; 55:6244-50.

7 Wang $Y X, X u L$, Zhang $X H$, et al. Five-year change in intraocular pressure associated with changes in arterial blood pressure and body mass index. The beijing eye study. Plos One 2013:8:e77180.
8 Shiose Y. The aging effect on intraocular pressure in an apparently normal population. Arch Ophthalmol 1984:102:883-7.

9 Klein BE, Klein R, Knudtson MD. Intraocular pressure and systemic blood pressure: Iongitudinal perspective: the Beaver Dam Eye Study. Br J Ophthalmol 2005:89:284-7.

10 SY W, Nemesure B, Hennis A. Barbados Eye Studies G. Nine-year changes in intraocular pressure: the Barbados Eye Studies. Arch Ophthal 2006:124:1631-6.

11 Hennis A, Wu SY, Nemesure B, et al. Barbados Eye Studies Group. Hypertension, diabetes, and longitudinal changes in intraocular pressure. Ophthalmology 2003:110:908-14

12 Chan EW, Li X, Tham YC, et al. Glaucoma in Asia: regional prevalence variations and future projections. Br J Ophthalmol 2016;100:78-85.

13 Tham YC, Li X, Wong TY, et al. Global Prevalence of Glaucoma and Projections of Glaucoma Burden through 2040: A Systematic Review and Meta-Analysis. Ophthalmology 2014

14 Gabelt BT, Kaufman PL. Changes in aqueous humor dynamics with age and glaucoma. Prog Retin Eye Res 2005;24:612-37.

$15 \mathrm{Ho} \mathrm{H}$, Shi Y, Chua J, et al. Association of systemic medication use with intraocular pressure in a multiethnic Asian population: the Singapore Epidemiology of Eye Diseases Study. JAMA Ophthalmol 2017:135:196-202.

16 Khawaja AP, Chan MP, Broadway DC, et al. Systemic medication and intraocular pressure in a British population: the EPIC-Norfolk Eye Study. Ophthalmology 2014;121:1501-7.

17 Zhao D, Cho J, Kim MH, et al. The association of blood pressure and primary openangle glaucoma: a meta-analysis. Am J Ophthalmol 2014;158:615-27.

18 Foong AW, Saw SM, Loo JL, et al. Rationale and methodology for a population-based study of eye diseases in Malay people: the Singapore Malay eye study (SiMES). Ophthalmic Epidemiol 2007;14:25-35.

19 Lavanya R, Jeganathan VS, Zheng Y, et al. Methodology of the Singapore Indian Chinese Cohort (SICC) eye study: quantifying ethnic variations in the epidemiology of eye diseases in Asians. Ophthalmic Epidemiol 2009;16:325-36.

20 Rosman M, Zheng Y, Wong W, et al. Singapore Malay Eye Study: rationale and methodology of 6 -year follow-up study (SiMES-2). Clin Exp Ophthalmol 2012:40:557-68.

21 Sabanayagam C, Yip W, Gupta P, et al. Singapore Indian Eye Study-2: methodology and impact of migration on systemic and eye outcomes. Clin Exp Ophthalmol 2017;45:779-89.

22 Chua J, Tham YC, Liao J, et al. Ethnic differences of intraocular pressure and central corneal thickness: the Singapore Epidemiology of Eye Diseases study. Ophthalmology 2014;121:2013-22.

23 Department of Statistics MoTal, Republic of Singapore. Census of Population 2000 Statistical Release 1: Demographic Characteristics. In: Statistics Do. ed, Singapore, 2001

24 Ying GS, Maguire MG, Glynn R, et al. Tutorial on biostatistics: linear regression analysis of continuous correlated eye data. Ophthalmic Epidemiol 2017; $24: 130-40$.

25 Glynn RJ, Rosner B. Regression methods when the eye is the unit of analysis. Ophthalmic Epidemiol 2012;19:159-65.

26 Chua J, Baskaran M, Ong PG, et al. Prevalence, risk factors, and visual features of undiagnosed glaucoma: the Singapore Epidemiology of Eye Diseases Study. JAMA Ophthalmol 2015:133:938-46.

27 Åström S, Stenlund H, Lindén C. Intraocular pressure changes over 21 years - a longitudinal age-cohort study in northern Sweden. Acta Ophthalmol 2014;92:417-20.

28 Burgoyne CF, Downs JC, Bellezza AJ, et al. The optic nerve head as a biomechanical structure: a new paradigm for understanding the role of IOP-related stress and strain in the pathophysiology of glaucomatous optic nerve head damage. Prog Retin Eye Res 2005:24:39-73.

29 Burgoyne CF, Downs JC. Premise and prediction-how optic nerve head biomechanics underlies the susceptibility and clinical behavior of the aged optic nerve head. J Glaucoma 2008;17:318-28.

30 Toris CB, Yablonski ME, Wang YL, et al. Aqueous humor dynamics in the aging human eye. Am J Ophthalmol 1999;127:407-12.

31 Jonas JB, Aung T, Bourne RR. Glaucoma. Lancet 2017.

32 Poulter NR, Prabhakaran D, Caulfield M. Hypertension. Lancet 2015;386:801-12

33 Kiel JW, Hollingsworth M, Rao R, et al. Ciliary blood flow and aqueous humor production. Prog Retin Eye Res 2011;30:1-17.

34 Kiel JW. The effect of arterial pressure on the ocular pressure-volume relationship in the rabbit. Exp Eye Res 1995:60:267-78.

35 Bayerle-Eder M, Kolodjaschna J, Wolzt M, et al. Effect of a nifedipine induced reduction in blood pressure on the association between ocular pulse amplitude and ocular fundus pulsation amplitude in systemic hypertension. $\mathrm{Br} J$ Ophthalmol 2005:89:704-8.

36 Ye S, Chang Y, Kim CW, et al. Intraocular pressure and coronary artery calcification in asymptomatic men and women. Br J Ophthalmol 2015:99:932-6. 